${ }^{\bullet}$ Entomologica Fennica. 21.XII.1990

\title{
Balancing sampling effort in pitfall trapping of carabid beetles
}

\author{
Jari Niemelä', Eero Halme \& Yrjö Haila
}

Niemelä, J., Halme, H. \& Haila, Y. 1990: Balancing sampling effort in pitfall trapping of carabid beetles. - Entomol. Fennica 1:233-238.

Samples of carabids were collected from two study areas in southern Finnish coniferous forest using continuous pitfall trapping throughout the breeding season. These were compared with samples from combinations of early and late season sampling periods $(5+5,10+10$ or $14+14$ days in each combination).

The same species were abundart in both the smaller samples from combinations of periods and in the whole season samples. There was considerable variation in the total catch of carabids among the 10-day samples ( $5+5$ days) which mainly reflected fluctuation in catch of the abundant species in the early season. About $42 \%$ of the total number of species was caught in every 10-day sample, $52 \%$ in every 20 -day sample, and $67 \%$ and $77 \%$ in every 28 -day sample. Most species not caught during the shorter trapping periods were scarce in the whole season sample ( $<10$ individuals). We suggest that samples obtained by trapping periods of 20 days or more were similar enough to the whole season sample to be used in several types of ecological studies.

Department of Zoology, University of Helsinki, P. Rautatiekatu 13, SF-00100 Helsinki, Finland

${ }^{1}$ Present address: Department of Entomology, University of Alberta, Edmonton, Alberta, Canada T6G $2 E 3$

\section{Introduction}

There is a controversy about the efficiency of pitfall trapping in sampling carabid beetles (den Boer 1986). As pitfall catches depend on both population sizes (Luff 1982, 1986) and activity of the beetles (Mitchell 1963, Greenslade 1964, Adis 1979, Desender \& Maelfait 1986, Halsall \& Wratten 1988), the catches are said to represent the "activity density" of carabids (Thiele 1977). Although pitfall catches of carabid beetles are affected by fluctuations in external factors, such as weather (Adis 1979, Ericson 1979), pooled samples from the whole activity season are thought to give a correct picture of local abundances of individual species (Baars 1979, den Boer 1986, Luff 1982).
In this paper we address the question how to allocate sampling effort to get as many representative samples as possible (Simberloff 1979). We study particularly the question of whether smaller samples taken from a whole season sample may be indeed representative of the carabid fauna. We compare the assemblage of carabid beetles collected by pitfall traps over the whole growing season with various subsamples taken from this catch for two different data sets collected in slightly different phytogeographical regions of southern Finnish coniferous forest. In the comparisons the following criteria were used: (a) catches of individual species, (b) the relative abundance of individual species in the samples, and (c) number of species. 


\section{Material and methods}

\subsection{Study area and sampling design}

The first data set is from the Musturi State Forest Reserve (area about 19 ha), located in northern Häme (about $62^{\circ} \mathrm{N}, 24^{\circ} \mathrm{E}$ ). The forest is a uniform stand of spruce (Picea abies) trees, more than 140 years old, interspersed with aspen (Populus tremula) and mountain ash (Sorbus aucuparia). The study area is described in more detail in Niemelä et al. $(1989,1990)$.

Three hundred pitfall traps (plastic cups, diameter $65 \mathrm{~mm}$, volume $170 \mathrm{ml}$ ) were arranged in a grid of $12 \times 25$ traps and operated continuously from 11 May through 23 October, 1985. Samples were collected every five days until 29 August, and thereafter less frequently (exact dates are given in Niemelä et al. 1989).

The second study area is located in a forest of about 400 ha near the city of Helsinki (about $60^{\circ} \mathrm{N}, 25^{\circ} \mathrm{E}$ ). Samples were taken in two separate sampling areas (areas A and B below) with four sampling sites in each area. We use the pooled samples from each of the areas in the analysis. The study area will be described in more detail elsewhere (Halme in prep.).

Sets of 15 traps, similar to those described above, were arranged in regular grids of $3 \times 5$ traps in the sites. Distance between grids was approximately $100 \mathrm{~m}$, and between the two areas approximately $500 \mathrm{~m}$. The traps were in operation continuously from 3 May through 18 October, 1988.

\subsection{Combinations of trapping periods and cal- culations}

Single carabid species have peaks in activity, and presumably in abundance, either in early summer or late summer (Lindroth 1945, Loreau 1985, Niemelä et al. 1989), which means that two sampling periods are necessarily required. Accordingly, we used periods from early summer (May-June) and from late summer (August) in both study areas for compiling the smaller samples.

In Musturi the sampling periods used for combinations of periods were May 26-31, May 31-June 5, June 5-10, 10-15 and 15-20 in the early season (hereafter called periods E1-E5),

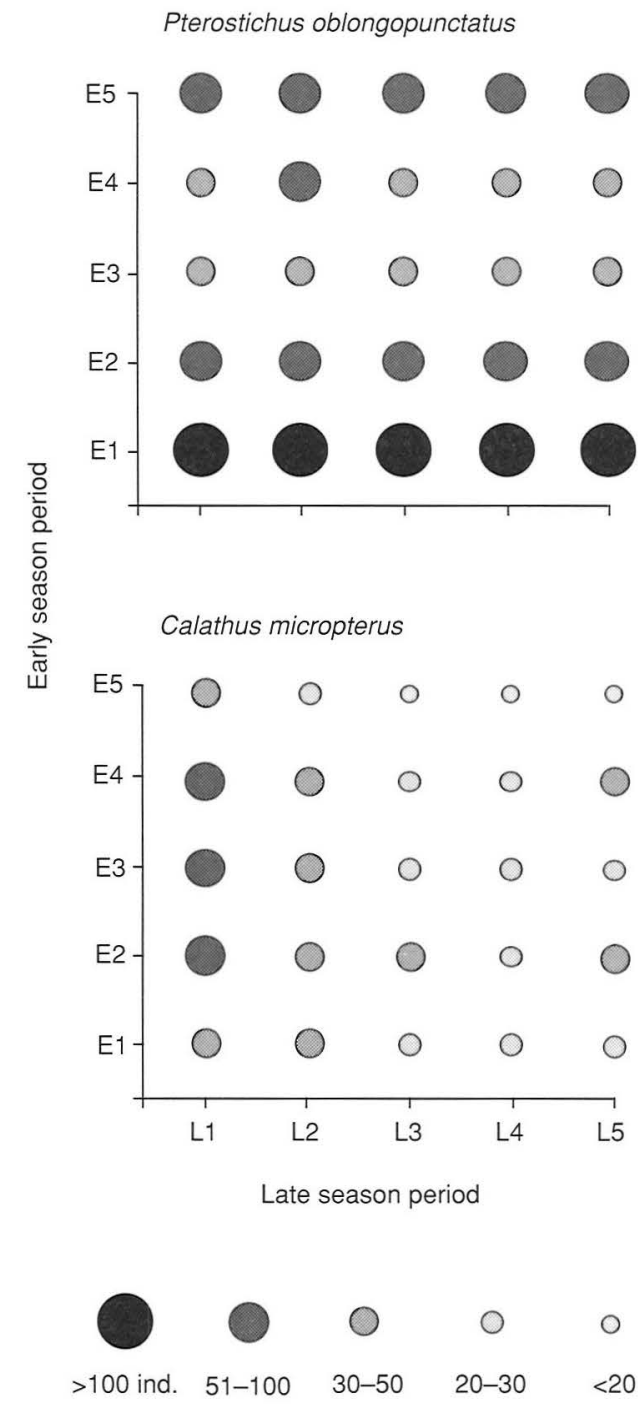

Fig. 1. Catches of Pterostichus oblongopunctatus (above) and Calathus micropterus (below) in the 25 ten-day combinations in Musturi. The sample from each of the early season periods (E1-E5, vertical axis) is combined with each of the late season periods (L1L5, horizontal axis).

and August 4-9, 9-14, 14-19, 19-24 and 24-29 in the late season (hereafter called periods L1-L5). Periods were combined in two ways: (1) Ten-day combinations. Each of the five periods in the early summer (E1-E5) was pooled with each of the late summer periods (L1-L5) giving 25 different combinations $(5 \times 5$ periods $)$ of 10 days each. 
(2) Twenty-day combinations. Each pair of successive periods in the early season $(\mathrm{E} 1+\mathrm{E} 2$ to $\mathrm{E} 4+\mathrm{E} 5)$ was combined with each pair of successive periods in the late season ( $\mathrm{L} 1+\mathrm{L} 2$ to $\mathrm{L} 4+\mathrm{L} 5)$ giving 16 combinations of $2+2$ periods, 20 days, each.

In Helsinki two periods from the early season (May 31-June 14 and June 14-28) and two periods from the late season (July 26-August 9 and August 9-23) were selected for the comparison and combinations were established by pooling each of the early season periods with each of the late season periods, this gave four combinations of two periods, 28 days, each.

\section{Carabid occurrence in combinations of trapping periods}

There was considerable variation in the catches of each of the five numerous species among the tenday combinations (Table 1). In Pterostichus oblongopunctatus this was mainly due to variation in numbers caught among the early season periods (Fig. 1). In other species, for instance Calathus micropterus, also the late season periods contributed to the variation (Fig. 1). The set of dominant species remained the same and their rank order was similar among the ten-day combinations (Kendall's coefficient of concordance (Zar 1984) $\mathrm{W}=0.614, \mathrm{p}<0.001: \mathrm{H}_{0}$ of random variation in rank order rejected) (Table 2).

Variation in catches of individual species among the twenty-day combinations was smaller than among ten-day combinations, but the ratio between maximum and minimum catches was still two to three fold (Table 1). The rank order of the abundant species was similar among the combinations (Kendall's W=0.729, $\mathrm{p}<0.001$ ) (Table 2). The proportions of the species were very similar in the ten-day, twenty-day and whole season samples.

In Helsinki the variation in the catches among the 28-day combinations was comparable to that of the 20-day combinations in Musturi (Table 1). Moreover, the species rank order was similar among the combinations of periods within both

Table 1. The mean catch, standard deviation, ratio between the maximum and minimum catch, and proportions in the combinations (c\%) and in the whole season (w\%) sample of the five most numerously caught carabid species ( $>5 \%$ of the sample) among the 25 ten-day combinations and in the 16 twenty-day combinations in Musturi. The six most numerous species in the four 28-day samples are given separately for areas A and B in Helsinki.

\begin{tabular}{|c|c|c|c|c|c|c|c|c|c|c|}
\hline & \multicolumn{5}{|c|}{ 10-day combinations } & \multicolumn{5}{|c|}{ 20-day combinations } \\
\hline & Mean & $S D$ & $\max / \min$ & $\mathrm{c} \%$ & $w \%$ & Mean & $S D$ & $\max / \min$ & $\mathrm{C} \%$ & $w \%$ \\
\hline Pt. oblongopunctatus & 71 & 35.1 & 3.7 & 42 & 35 & 127 & 45.6 & 2.4 & 40 & 35 \\
\hline Calathus micropterus & 31 & 11.4 & 5.1 & 19 & 23 & 63 & 16.0 & 2.3 & 20 & 23 \\
\hline Notiophilus biguttatus & 22 & 13.0 & 5.0 & 11 & 12 & 39 & 13.0 & 2.5 & 11 & 12 \\
\hline Leistus terminatus & 18 & 6.7 & 4.3 & 13 & 12 & 36 & 6.7 & 1.6 & 12 & 12 \\
\hline Cychrus caraboides & 16 & 5.6 & 4.5 & 10 & 11 & 32 & 8.7 & 2.6 & 10 & 11 \\
\hline \multirow[t]{2}{*}{ Remaining species } & 9 & 4.9 & 10.5 & 5 & 7 & 18 & 7.0 & 5.3 & 6 & 7 \\
\hline & \multicolumn{5}{|c|}{ Area A } & \multicolumn{5}{|c|}{ Area B } \\
\hline Calathus micropterus & 384 & 202.2 & 2.7 & 37 & 38 & 342 & 66.6 & 1.6 & 30 & 34 \\
\hline Amara brunnea & 185 & 41.1 & 1.6 & 18 & 16 & 116 & 13.2 & 1.2 & 10 & 8 \\
\hline Trechus secalis & 118 & 44.5 & 2.0 & 11 & 7 & 58 & 7.5 & 1.3 & 5 & 4 \\
\hline Pt. oblongopunctatus & 108 & 16.1 & 1.3 & 10 & 16 & 127 & 46.6 & 1.8 & 11 & 16 \\
\hline Patrobus atrorufus & 97 & 47.2 & 3.0 & 9 & 7 & 290 & 95.1 & 2.9 & 25 & 19 \\
\hline Carabus hortensis & 52 & 17.8 & 2.1 & 5 & 4 & - & - & - & - & - \\
\hline Pt. melanarius & - & - & - & - & - & 64 & 13.3 & 1.5 & 6 & 5 \\
\hline Remaining species & 88 & 22.4 & 1.7 & & & 152 & 7.0 & 11.1 & & \\
\hline
\end{tabular}


Table 2. Number of times that each of the five abundant species in Musturi was the most numerously caught species, the second most numerous one etc. among the 25 ten-day and 16 twenty-day combinations. For instance, $P$. oblongopunctatus was the most abundantly caught species in 23 of the 25 ten-day combinations.

\begin{tabular}{lrrrrrrrrrr}
\hline & \multicolumn{4}{c}{ 10-day combinations } & \multicolumn{3}{c}{ 20-day combinations } \\
\multicolumn{1}{r}{ Rank: } & 1 & 2 & 3 & 4 & 5 & 1 & 2 & 3 & 4 & 5 \\
\hline Pt. oblongopunctatus & 23 & 2 & - & - & - & 16 & - & - & - & - \\
Calathus micropterus & 2 & 16 & 4 & 1 & 2 & - & 14 & 2 & - & - \\
Leistus terminatus & - & 1 & 9 & 10 & 5 & - & - & 5 & 8 & 3 \\
Notiophilus biguttatus & - & 6 & 5 & 6 & 8 & - & 2 & 5 & 3 & 6 \\
Cychrus caraboides & - & - & 7 & 8 & 10 & - & - & 4 & 5 & 7 \\
\hline
\end{tabular}

areas $(\mathrm{W}=0.85, \mathrm{p}=0.004$ in area $\mathrm{A}$, and $\mathrm{W}=0.95$, $\mathrm{p}=0.002$ in area $\mathrm{B}$ ) and the proportions of the species were relatively similar in the whole season sample and the combinations.

Only five of 22 species were caught in every ten-day sample (Table 3). The eight species absent from all ten-day and all twenty-day combinations were rare, with $<5$ individuals of each species caught in the whole season sample. Among the 28-day combinations in Helsinki, a higher proportion of species were found in all combinations than among the shorter periods in Musturi. Similarly, the species absent from all or some combinations were rare (in area $\mathrm{A}<9$ individuals/ species and in area $B<7$ individuals/species in the whole season sample).

Naturally, numbers of specimens and species in the samples from combinations increased as the length of the trapping period increased (Table 4). However, variation in catch sizes even among the 20 -day and 28-day combinations was considerable because of high seasonal variation in catches of the abundant species. Variation in number of species was much lower than in number of specimens.

\section{Applicability of pitfall trapping in ecological studies}

These comparisons can be related to realistic expectations about similarity of samples drawn from the same population. The Musturi trap grid was divided into 6 regular blocks of 48 traps each and percentage similarity among them using the whole season data was calculated. The average similarity value of the Renkonen index, 0.83 , was
Table 3. Number of species present in all the combinations, in some of them or absent from all of them in samples from the 10-day and 20-day combinations in Musturi, and in samples from the 28-day combinations in area $A$ and $B$ in Helsinki.

\begin{tabular}{|c|c|c|c|c|}
\hline & Mus & turi & Hels & inki \\
\hline & $10-d$ & 20-d. & $A$ & B \\
\hline Present all comb. & 5 & 9 & 16 & 17 \\
\hline Present some comb. & 9 & 5 & 6 & 7 \\
\hline Absent all comb. & 8 & 8 & 3 & 7 \\
\hline Proportion absent & 36.4 & 36.4 & 12.0 & 22.6 \\
\hline $\begin{array}{l}\text { Species in whole } \\
\text { season sample }\end{array}$ & 22 & 22 & 25 & 31 \\
\hline
\end{tabular}

Table 4. Mean catch and mean number of species with standard deviation, and proportion (\%) of the mean of the whole season sample in the different combinations of trapping periods.

\begin{tabular}{lrrrrrr}
\hline \multirow{2}{*}{$\begin{array}{l}\text { Combi- } \\
\text { nation }\end{array}$} & \multicolumn{3}{c}{ Mean } & SD & \multicolumn{4}{c}{ No. of species } \\
& & & & Mean & SD & $\%$ \\
\hline 10-day & 167.4 & 48.3 & 7.0 & 9.2 & 1.3 & 41.8 \\
20-day & 315.0 & 62.2 & 13.2 & 11.5 & 0.7 & 52.3 \\
28-day, A & 1030.0 & 327.6 & 23.5 & 19.3 & 1.7 & 77.2 \\
28-day, B & 1146.0 & 185.4 & 21.9 & 20.8 & 1.0 & 67.1 \\
\hline
\end{tabular}

higher than the average value between both the ten-day combinations (0.66) and the twenty-day combinations $(0.72)$ vs. the whole season sample in Musturi, but similar to the values obtained between the 28-day combinations and the whole season sample in Helsinki (area A: 0.85, area B: 0.84 ). Thus, shorter sampling periods may depict the fauna as accurately as a spatially limited sample from the total pool. 
Similarity between smaller samples and the whole season sample increased and the variation in the abundance rank of the species decreased with increasing length of the sampling period. Total catch in samples from ten-day combinations was heavily influenced by variation in catches of the numerously caught species, caused for instance by fluctuations in weather conditions in the early season (Niemelä et al. 1989). These fluctuations were evened out by increasing the length of the sampling period. Thus, the ten-day combinations covered too short a part of the season to reliably represent the whole season sample, but twenty-day and 28-day combinations were more similar to the whole season sample.

None of the smaller samples included all species caught in the whole season sample, and so sampling over the whole season gives a more comprehensive picture of species composition than does shorter trapping periods. However, whole season sampling may be logistically impossible when manpower is limited and there is a need for large data sets. Such studies may include mapping the distribution of species over different habitats in extensive areas, or survey studies to identify and locate potentially threatened species (e.g. Nicholls 1989). Use of sampling periods shorter than the whole season, may be the only realistic possibility and is legitimate provided the efficiency of the procedure is known. Therefore, sampling design should be based on a priori knowledge of species biology, for instance, seasonal activity patterns of the species (for similar arguments about sampling of waterstriders, see Spence 1980).

It is critical that the sampling period be chosen with information about the annual activity cycles, to obtain representative samples especially for species with a short activity period (such as $P$. oblongopunctatus and Leistus terminatus in this study). Unfortunately, differences in activity periods of the species underscore that the concept of "community structure" is ambiguous in carabid beetles. It is unrealistic to pool the whole season because early season species, such as $P$. oblongopunctatus, and late season species, such as $L$. terminatus, may overlap very little temporally as adults and thus the adults have minimal possibility for interaction (see also Loreau 1986). On the other hand, the different developmental stages of the species may overlap and thus potentially interact with each other. For instance, in our study adults of $P$. oblongopunctatus and larvae of $L$. terminatus have most likely occurred simultaneously. Unfortunately, too little is known about the ecology of larvae to assess the importance of interactions between them and adults (Spence 1979).

On the basis of these analyses we argue that pitfall trapping during periods shorter than the entire activity season is an adequate sampling method to address several types of ecological problems especially those that focus on individual species or groups of locally abundant species. These studies include monitoring population fluctuations, comparing geographic differences in occurrence of individual species, and examining environmental correlates of distribution patterns.

It is an urgent challenge for field biologists to develop survey methods applicable in assessing environmental problems, for instance, in monitoring the effects of climate changes (Eberhardt 1976, Holling 1978, Stewart-Oaten et al. 1986). Adequate procedures for collecting of observations over the long-term must be developed (Haila 1991). Pitfall trapping used in a standardized way has the potential of becoming such a method.

Acknowledgements. Our sincere thanks are due to Esa Ranta, Juha Siitonen and John Spence for constructive comments on the manuscript. J. Spence kindly revised the English. Pekka Punttila and Timo Pajunen are thanked for help in the field work. The study was financed by the Academy of Finland and the Emil Aaltonen Foundation (grants to JN). JN also wants to acknowledge a Post Doctoral Fellowship from the Killam Foundation which made the final preparation of the paper possible.

\section{References}

Adis, J. 1979: Problems of interpreting arthropod sampling with pitfall traps. - Zool. Anz. 202:177-184.

Baars, M. A. 1979: Catches in pitfall traps in relation to mean densities of carabid beetles. - Oecologia (Berl.) 41:25-46.

den Boer, P. J. 1986: Carabids as objects of study. — In: den Boer. P. J., Luff, M., Mossakowski, D. \& Weber, F. (eds.): Carabid beetles, their adaptations and dynamics:539-551. Gustav Fischer, Stuttgart. 
Desender, K. \& Maelfait, J.-P. 1986: Pitfall trapping within enclosures: a method for estimating the relationship between the abundances of coexisting carabid species Coleoptera: Carabidae. - Holarctic Ecology 9:245-250.

Eberhardt, L. L. 1976: Quantitative ecology anc impact assessment. - J. Env. Management 4:27-70.

Ericson, D. 1979: The interpretation of pitfall catches of Pterostichus cupreus and Pt. melanarius Coleoptera, Carabidae in cereal fields. - Pedobiologia 19:320-328.

Greenslade, P. J. M. 1964: Pitfall trapping as a method for studying populations of Carabidae Coleoptera. - J. Animal Ecology 33:301-310.

Haila, Y. 1991: Measuring nature. Quantitative data in the research traditions of field biology. - In: Clarke, A. \& Fujimura, J. (eds.): The right tools for the job in twentieth century life sciences: materials, techniques, instruments, models and work organization. Princeton Univ. Press, Princeton, NJ. (in press).

Halsall, N. B. \& Wratten, S. D. 1988: The efficiency of pitfall trapping for polyphagous predatory Carabidae. — Ecol. Entomol. 13:293-299.

Holling, C. S. (ed.) 1978: Adaptive environmental assessment. John Wiley \& Sons, London.

Loreau, M. 1986: Niche differentiation and community organization in forest carabid beetles. - In: den Boer, P. J., Luff, M., Mossakowski, D. \& Weber, F. (eds.): Carabid beetles, their adaptations and dynamics:465-487. Gustav Fischer, Stuttgart.

Lindroth, C. H. 1945: Die Fennoskandischen Carabidae, I. —Göteborgs Kungliga Vetensk. Handl. B4(1): 1-710.

Luff, M. L. 1982: Population dynamics of Carabidae. Ann. appl. Biol. 101:164-170.

- 1986: Aggregation of some Carabidae in pitfall traps. - In: den Boer, P. J., Luff, M., Mossakowski, D. \& Weber, F. (eds.): Carabid beetles, their adaptations and dynamics:385-397. Gustav Fischer, Stuttgart.
Mitchell, B. 1963: Ecology of two carabid beetles, Bembidion lampros Herbst and Trechus quadristriatus Schrank. II. Studies on populations of adults in the field, with species reference to the technique of pitfall trapping. J. Animal Ecology 32:377-392.

Nicholls, A. O. 1989: How to make biological surveys go further with generalised linear models. - Biol. Conserv. 50:51-75.

Niemelä, J., Haila, Y., Halme, E., Pajunen, T. \& Punttila, P. 1989: The annual activity cycle of carabid beetles in the southern Finnish taiga. — Ann. Zool. Fennici 26:35-41.

- 1990: Small-scale heterogeneity in the spatial distribution of carabid beetles in the southern Finnish taiga. J. Biogeogr. submitted.

Simberloff, D. S. 1979: Rarefaction as a distribution-free method of expressing and estimating diversity. - In: Grassle, J. F., Patil, G. P., Smith, W. K. \& Taillie, C. (eds.): Ecological diversity in theory and practice:159-176. Statistical Ecology Series, vol. 6, International Co-operative Publishing House, Fairland, Maryland.

Spence, J. R. 1979: Riparian carabid guilds — a spontaneous question generator. - In: Erwin, T. L., Ball, G. E. \& Whitehead, D. R. (eds.): Carabid beetles: their evolution, natural history and classification:525-537. W. Junk, The Hague.

- 1980: Density estimation for water-striders Heteroptera: Gerridae. - Freshwater Biology 10:563-570.

Stewart-Oaten, A., Murdoch, W. W. \& Parker, K. R. 1986: Environmental impact assessment: "pseudoreplication" in time? - Ecology 67:929-940.

Thiele, H-U. 1977: Carabid beetles in their environments. Springer Verlag, Berlin.

Zar, J. H. 1984: Biostatistical analysis. Prentice-Hall Inc. New Jersey, (paperback). 718 pp.

Received 18.I.1990 